\title{
Measuring Social and Psychological Outcomes from Activation Labour Market Programmes in Higher Education: A Pilot Study.
}

\author{
Vanessa Long Hogarty \\ Dublin Business School \\ PhD candidate, Trinity College Dublin \\ Dublin, Ireland \\ Dr Conor Mc Guckin \\ Assistant Professor, \\ School of Education, Trinity College Dublin \\ Dublin, Ireland
}

(C) Author(s). This work is licensed under the Creative Commons Attribution-NonCommercialShareAlike 4.0 International License. To view a copy of this license, visit https://creativecommons.org/licenses/by-nc-sa/4.0/ .

\begin{abstract}
Following the 2008 recession, Ireland experienced unemployment rates as high as 15\% (McGuinness, O'Connell and Kelly, 2014). Policy responses have been through the introduction of upskilling and reskilling through activation labour market policies (ALMPs) in the higher education sector (Department of Education and Skills, 2015). The evidence to date regarding the efficacy of such interventions (e.g., Springboard+) has been concerned with blunt measurements of progression rates, labour market entry, and earnings. The present study explored social capital and social well-being among a sample of 101 participants of Springboard+ programmes at one higher education provider in Dublin. The primary objective of the pilot study is to create and test a research method informed by well validated indicators to inform a larger national study.

Keywords: unemployment; upskilling; reskilling; activation labour market policies; Springboard+; higher education; social outcomes; social capital; social policy; measurement
\end{abstract}

\section{Introduction}

Following the 2008 recession, Ireland experienced unemployment rates as high as $15 \%$ (McGuinness, O'Connell, and Kelly, 2014). Policy responses related to the upskilling and reskilling of the workforce were operationalised through the introduction of activation labour market policies (ALMPs) in the higher education sector (Department of Education and Skills: DES, 2015). The evidence to date regarding the efficacy of such interventions (e.g., Springboard+) has been concerned with blunt measurements of progression rates, labour market entry, and earnings. However, as would be generally expected of any intervention with life-long or life-wide skills and 
personal development components, the "voice" of the participants was not recorded. So as to supplement existing knowledge of the efficacy of one such programme (Springboard+), the present study explored social capital and social wellbeing among a sample of 101 participants enrolled at one higher education provider in Dublin. The primary objective of this pilot study is to test and trial a questionnaire developed from well validated items.

\section{Research context}

From crisis spending to labour market activation programmes

So as to generate data and provide a picture of the effects of the worldwide recession on the education sector, the Organisation for Economic Cooperation and Development (OECD) conducted the Education Today Crisis Survey 2010 (Damme and Kärkkäinen, 2011). In the survey, Ireland cited "alleviate unemployment", "meet education demands", and "prepare for future growth" as reasons for labour activation programmes or "stimulus spending" in higher education. Throughout the survey responses, "crisis related" was cited as the most prominent reason for increased spending in higher education.

\section{What does this "crisis spending" look like in Ireland?}

Initially introduced for workers who had become unemployed during the recession, the "Springboard" initiative provides part-time upskilling and reskilling within the higher education sector in Ireland (Higher Education Authority: HEA, 2016). Officially launched in 2011, Springboard represents one-fifth of the Government's "skills to work programme" initiative which includes five programmes of labour activation - the others being JobBridge, Momentum, JobPlus, and Skillnet (DES, 2015). Springboard is closely aligned to the National Skills Strategy goals of meeting future demands within certain sectors and enhancing the knowledge-based workforce. Initially offering 6,000 places in 34 public and private higher education institutions across Ireland, this opened up opportunities to cohorts of unemployed who would otherwise be unable to enter higher education. Managed by the HEA on behalf of the DES, funding is provided by the Irish government and the European Social Fund (programme for employment, inclusion and learning 2014-2020). According to the DES (2018), over $€ 161$ million has been invested in the newly rebranded "Springboard+" with over 47,000 places funded. In 2018, there are an additional 25\%, compared to 2017; meaning over 8,000 places are now available for those eligible under the new criteria.

Entry to Springboard courses, unlike traditional admission requirements for higher education, is not dependant on one's academic history. Initially, the target participants were those who became unemployed and those without higher education qualifications (HEA, 2015). Eligible participants were required to be unemployed and actively seeking employment. In 2012, additional places were offered, and eligibility was extended to other cohorts of social welfare recipients - including those who were self-employed. In 2018, the criteria for inclusion has widened to include $100 \%$ funded places for "homemakers" and unemployed, and both full- and part-time employees 
with $90 \%$ funding (DES, 2018). Springboard+ engages students from certificate level courses to masters level courses in a full- and part-time capacity, with courses aimed at the ICT, medical technologies, hospitality, financial, and construction sectors. During the period 2011-2016, over 40,500 funded places were filled, with the majority of applicants being over 30 years of age. Interestingly, a large number of students were re-entering higher education, with $81 \%$ already holding a level 6-10 award on the National Framework for Qualifications as they commenced their Springboard course.

The HEA (2016) reported a completion rate of $72 \%(n=22,531)$ with $80 \%$ of these leaving the live register. A review of Springboard 2011-2016 found that $88 \%$ of the places had been taken up, with an increased uptake of online / distance courses. Building on the initial success of this labour market activation programme and keeping in line with the goals of the ICT Action Plan (DES, 2011a) and the Expert Group on Future Skills Needs (EGFSN) report in the ICT Action Plan, Springboard+ allocated extra places for ICT courses. In response to the national shortage of ICT graduates that was highlighted in the ICT Action Plan (DES, 2011a), Springboard has further expanded to include more cohorts of eligible participants. Once limited to those who were unemployed, Springboard now addresses the need to upskill / reskill so as to increase employability in areas with skills shortages. In 2017 / 2018, both full- and part-time courses are now available, opening opportunities to homemakers, selfemployed as well as those already in employment and wishing to change careers. This inclusion of employed learners and homemakers supports the observation of social policy theorists - in that people are moving away from traditional decision making and upward progression in one's career to a more "sideways progression" to new sectors through up/reskilling (McArdle, Briscoe, and Hall, 2007). Overall, the number of courses in participating higher education providers - both public and private - has grown from 208 to 245 with over 8,000 places available on over 245 courses (DES, 2017, 2018).

\section{What is the current picture of the Springboard student?}

Whilst reporting on the Springboard+ programme is often based on metrics regarding, for example, participation rates, little is known about the personal, familial, and community / societal impacts of participation on Springboard+ programmes. The HEA currently reports upon data sourced from their application management system and periodic participant surveys (HEA, 2016). There are insufficient opportunities for participants to report upon their experiences in the existing form of testimonials and vague "sentiment" survey questions. Latest numbers from the 2016 report show some positive comments from participants. However it should be noted that the collated testimonials are only one to two pages in length for the period 2011 to 2016 . The majority of previous participants surveyed "strongly agreed" $(46 \%, n=1,012)$ or "agreed" $(46 \%, n=1,018)$ that the course positively impacted upon their lives (HEA, 2016). It can be argued that these numbers alone - although positive, are not enough. Fundamental questions remain - for example: how has their life been positively 
impacted? Have they had a second chance at higher education? Have they developed deep social networks or understanding of their experience? Has their social capital and world view positively changed?.

Although the survey is detailed in nature, the HEA themselves acknowledge within their reports that it does not allow for lived experiences. One of the recommendations of the Cassells report (Investing in National Ambition: A Strategy for Funding Higher Education: DES, 2016) is increased funding for higher education institutions to facilitate both social and economic developments. Furthermore, the Cassells report states that there must be verifiable results of the above developments (OECD, 2017).

To date, there are a plethora of progression and employment statistics from the HEA only offering short free text responses from participants (HEA, 2016). There still remains a gap in the data demonstrating the lived experiences of the Springboard students. Ireland has a long tradition of understanding the issues affecting social exclusion and the role that educational opportunities can play in reducing marginalisation amongst society's most vulnerable groups. The OECD reports considerably on social outcomes and the value of education across more than 50 countries.

However, it is not sufficient to report voiceless statistics regarding progression and employment status after completing such programmes. Such a unique cohort of students cannot be understood through quantitative measures alone. The human experience and developments after unemployment during the recession and / or the opportunity to reskill through higher education is a new experience; one which can only be understood through lived experiences. Exploring the impact of government policies through a mixed-methodological approach can contribute to the evidence on the impact of Springboard programmes for participants.

\section{Why address concepts of well-being, social capital and lived experience?}

From a European perspective, Stiglitz, Sen, and Fitoussi (2009, p. 41) argue that a progressive approach which builds on the traditional GDP measurement can "enrich" the policy process. This is then reiterated in the OECD (2011) "How's Life?" biannual report of which the social capital interpretations feature as indicators. The interpretations of social capital conceptualized by the OECD as most appropriate to the research programme are: 1) personal relationships; 2) civic engagement; 3) trust and cooperative norms; and 4) social network support. As argued by Scrivens and Smith (2013), these four concepts are high policy priorities as they are detrimental to economic production, mental health, well-being, and civic participation.

Table 1: OECD How's Life? Measuring Well-being indicators 2011 Individual well-being

Quality of life Material Conditions

Health status Income and wealth 


\begin{tabular}{|l|l|}
\hline Work and life balance & Jobs and earnings \\
\hline Education and skills & Housing \\
\hline Social connections & \\
\hline Civic engagement and governance & \\
\hline Environmental quality & \\
\hline Personal security & \\
\hline Subjective well-being & \\
\hline Sustainability of well-being over time & \\
\hline Natural capital & Human capital \\
\hline Economic capital & Social capital \\
\hline
\end{tabular}

From: OECD (2011). How's Life?: Measuring Well-being, OECD publishing

Following the 2008 global recession, Ireland experienced unemployment rates as high as 15\% (McGuinness, O'Connell, and Kelly, 2014, p. 426). As set out by Ireland's National Skills Strategy, Ireland's social policies have responded to levels of unemployment through the introduction of upskilling and reskilling through labour activation programmes in higher education provision (DES, 2015, p. 46). Furthermore, higher education is not only recognised as an exit pathway from unemployment, but the positive contributions to socio-economic outcomes and well-being are emphasised in current policies such as National Strategy for Higher Education 2030 (DES, 2011b). The upskilling and reskilling of the unemployed within the public and private educational institutions can be seen as a progressive move towards the government's future goal of building a knowledge-based economy.

\section{Perspectives on activation labour market programmes and well-being}

While there is a scarcity of academic literature directly addressing ALMPs within the arena of higher education, there are key pieces which address well-being - or as Andersen (2008) calls it - "indirect effects" of ALMP training/government upskilling programmes. Both Andersen (2008) and Sage (2014) conducted secondary analysis of the British Household Panel Survey to answer the question of "Do ALMPs increase well-being and social capital?" In order to assess these non-economic outcomes, in both cases a fixed effects model was used. For Sage (2014), whilst there was a positive effect and overall increase of well-being among ALMP participants, no improvement was found in their levels of social capital. However, Andersen (2008) omitted the social capital indicator and reported higher well-being amongst ALMP participants in comparison to the non-participant control group. Sage (2014) acknowledges that the lack of social capital improvement may be caused by restrictions within the dataset and absence of some social capital indictors. Another limitation proposed by Andersen (2008) relates to the characteristics of individual participants and levels of enthusiasm. Other studies, such as that by Creed, Bloxsome, and Johnston (2001) approached the concept of well-being through the measurement of self-esteem and self-efficacy. Although Creed et al. (2001) reported relationships between upskilling programmes for the unemployed and well-being, this measurement alone did not align with the concept of well-being in modern social policy (OECD, 
2011). One output from Creed et al. (2001) was the recommendation to uncover participant's experiences.

Using a human capital theory approach, Nordlund (2011) assessed the impact of educational training ALMPs in Sweden. Government longitudinal quantitative data was analysed to seek an understanding into who benefited the most from ALMPs. Findings suggested that participation in ALMPs positioned individuals in a more positive labour market position and acted as a stepping stone to further educational training.

As higher education is a catalyst for individual well-being and increased quality of life, Strandh (2000) adds that the transition from unemployment to higher education results in a significant increase to an individual's positive mental health. Gained "predicted status" through education is said to provide security and well-being. Education is said to be the forefront predictor in the measurement of trust, social involvement, and social capital (Helliwell and Putnam, 2007). Milligan, Moretti, and Oreopoulos (2004) have shown that higher levels of education attainment results in higher levels of social and community engagement. More recently, the OECD (2010) acknowledges that education facilitates improved mental well-being through the acquisition of social capital. The results of upskilling and reskilling through higher education is well documented in both Irish social policy and international level.

\section{Lived experience: Analysis through Bourdieusian Perspective}

The current research programme is an "a priori" planned mixed-methodological set of research studies that seeks to attain rich, in-depth data from interviews regarding the lived experience of Springboard students. The interviews occur on completion of the programme. With regards to the lived experiences of this unique cohort of "unemployed learners" and learners re-entering education to reskill / upskill, we set out an argument for a Bourdieusian approach. Considered the founding father of "social capital" (Scrivens and Smith, 2013), the work of French sociologist Pierre Bourdieu will be central to the qualitative analysis framework. In their analysis of the lived experience of Erasmus students and employability, Botas and Huisman (2013) advocated a Bourdieusian analytic approach as an appropriate tool to discover lived experiences. It is proposed to utilise this approach to explore the lived experience of the unemployed learner / Springboard student in higher education activation programmes. This will provide a deeper understanding of their participation in higher education, concerning how they make sense of their social capital accumulation, if it impacted on their Habitus, and if they experienced embourgeoisement. Harker (1984, p. 118) argues that embourgeoisement occurs when the focus on "employability" in higher education is a mechanism to shape individuals to fit the existing or expected Habitus. Although the "unemployed learner" has a unique Habitus shaping their disposition and how they describe themselves. Reay (2004) describes how higher educational experiences can build one's social capital. 


\section{Methodology}

\section{Sampling method}

Purposive sampling was chosen as the participant population must satisfy the inclusion criteria: being over the age of 18 and commencing a higher education programme funded by Springboard. In order to gain access to the participants, gatekeepers in the form of support staff were presented with information sheets and a copy of the questionnaire. Once access was granted, groups of students fitting the inclusion criteria were invited to take part in the study.

\section{Participants}

A total of $\mathrm{N}=101$ eligible students participated in the study. Participants were enrolled in Springboard funded undergraduate programmes ranging from level 6 to level 8. These QQI accredited programmes were being undertaken on both a part- and fulltime basis.

\section{Measures}

\section{Demographics}

A quantitative questionnaire was used to collect demographic information including level of education, labour market status, and age of commencement. The demographic questions used were adapted from EuroStat and EU-SILC indicators to allow for future European comparisons.

\section{Social capital}

The questionnaire also measured levels of social capital. Funded through the European Commission Directorate-General for Employment, the OECD has compiled a databank of 1,300 questions appropriate in the measurement of social capital. A plethora of surveys - both official and unofficial - were collected and organised under the four themes of social capital (Scrivens and Smith, 2013).

In order to construct a survey which is both culturally appropriate and transferable, questions from the European Union Statistics on Income and Living Conditions (EUSILC) instrument managed by Eurostat were chosen. Questions were coded under the following four themes of social capital identified by the OECD: "personal relationships", "social network supports", "civic engagement", and "trust and cooperative norms" (Scrivens and Smith, 2003).

The databank was presented in an Excel format consisting of the social capital theme, variable category, question text, response text, and the name and date of the survey. The Excel databank allowed for filtering by themes to ensure all four social capital themes are included, resulting in 19 questions being identified for the survey.

The theme "personal relationships" is measured through six questions from the European Survey on Income and Living Conditions - Ad Hoc Module on Social 
Participation (2006) and European Survey on Income and Living Conditions - Ad Hoc Module on Well-Being (2013). The questions are likert scale in nature and concern both non face-to-face and face-to-face social contact.

The second theme "social network supports" is measured through three questions from the European Survey on Income and Living Conditions - Ad Hoc Module on Social Participation (2006) and European Survey on Income and Living Conditions - Ad Hoc Module on Well-Being (2013). The questions are categorical in nature and are concerned with perceived support.

The third theme is "civic engagement" and is measured through six categorical questions concerning associational involvement. All six questions are from the European Survey on Income and Living Conditions - Ad Hoc Module on Social Participation (2006).

The final theme "trust and cooperative norms" consists of four likert scale questions measuring generalised trust and trust in institutions. All of the questions are from the European Survey on Income and Living Conditions - Ad Hoc Module on Well-Being (2013).

\section{Well-being}

The Scale of Positive and Negative Experience (SPANE) was chosen to measure positive and negative feelings experienced during the previous four weeks. This scale was likert in nature with response options ranging from 1 (very rarely or never) to 5 (very often or always). In order to calculate an overall balance effect score, Diener et al (2009) recommend computing total scores for both positive and negative scores and then subtracting the negative score from the positive. Scores can range from -24 (indicating most unhappy) to 24 (being most happy).

The second scale used to measure well-being was The Flourishing Scale from Diener and Biswas-Diener (2009) - an eight-item well-being scale that measures self-reported optimism, self-esteem, and purpose. Eight likert scale items ranging from 1 (strongly disagree) to 7 (strongly agree) were computed to provide a score from 8 (lowest possible psychological strengths) to 56 (highest possible psychological strengths).

\section{Analysis}

Questionnaire responses were analysed using SPSS ${ }^{\mathrm{TM}}$ Version 24. Basic univariate analysis using frequencies and descriptive statistics were carried out, including age, level of education, labour market status, and sex of participants. The variable "labour market status" was recoded into two new variables: "employed" and "unemployed". This allowed for independent samples t-tests to be calculated to test for differences between the two groups on their well-being scales. 


\section{Ethics}

Ethical approval was granted by the Ethics Committee of the School of Education, Trinity College Dublin. All participants were reassured that participation was voluntary and the results would be completely anonymous.

\section{Results}

\section{Demographic profile of pilot study}

The average age of the Springboard student was 40 years $(S D=9.81)$, with an age range from 25 years to 65 years. There were slightly more females $(53.5 \%, n=54)$ than males $(46.5 \%, n=47)$ in the study.

The majority of participants $63 \%(n=63)$ were unemployed on commencement of the Springboard programme. While there were similar levels of unemployment between the sexes (females: $n=32$; males: $n=31$ ), the female respondents attained a higher level of education previous to the commencement of Springboard. High levels of educational attainment and participants reporting employment $23.8 \%(n=24)$ was indicative of the reskilling or "sideways progression" discussed by McArdle, Briscoe, and Hall (2007). The high level of previous education can also be explained by the ICT Action Plan 2014-2018 (DES, 2014) which pushes for more people to participate in ICT conversion courses. The participants in this research sample attended institutions where such conversion courses are on offer.

\section{Well-being}

An independent-samples t-test was conducted to compare mean scores of flourishing in employed and unemployed participants. There was a statistically significant difference between the scores for employed $(M=47.8, S D=5.7)$ and unemployed $(M$ $=41.8, S D=8.9)$ participants; $t(60.7)=3.892, p=0.000$. These results indicated that employment status on commencement of ALMPs had an effect of flourishing scores.

An independent-samples t-test was conducted to compare mean scores of positive and negative experiences in employed and unemployed participants. No statistically significant differences were found.

\section{Social capital}

When asked about levels of satisfaction with personal relationships, scores could range from 0 (not at all satisfied) to 10 (completely satisfied). Participants in employment $(n=24)$ reported higher levels of satisfaction $(M=7.1, S D=1.8)$ than their unemployed counterparts $(n=76: M=6.4, S D=2.0)$. When asked about their ability to ask others for help, the majority of employed $(79 \%, n=19)$ answered in the affirmative. Interestingly, the majority of unemployed $(79 \%, n=60)$ reported "yes", followed by $9 \%(n=7)$ stating "no" and $8 \%(n=6)$ reporting "don't know". When asked to rate their trust in the police from 0 (no trust at all) to 10 (complete trust), employed participants $(n=24)$ scored $M=5.5, S D=2.5$. Unemployed participants $(n=76)$ 
reported an average score of $M=5.1, S D=2.7$. The four measures or trust were computed into one overall trust score. An independent-samples t-test was conducted to compare mean scores of trust in employed and unemployed participants. No statistically significant differences were found.

\section{Limitations and future considerations}

The objective of this pilot study was to trial a questionnaire set developed from well validated items and to limit respondent fatigue. Completion time for the questionnaire booklet was quick (5 to 10 minutes to complete) and no problems were encountered. Questionnaires were presented in pencil and paper format with information for the participants to seek clarification or highlight any issues - if needed. No negative feedback or suggestions for improvement were received from the participants. This pilot study drew a sample from a higher education institution in Dublin city. For the main study, all 42 participating higher educational institutions will be invited to take part. A larger, more representative sample will greatly contribute to social policy of higher education and ALMP in Ireland and allow for full exploration of whether:

1. Participants in government ALMPs experience an increase in subjective well-being;

2. Compared to the employed, unemployed participants in government ALMPs experience higher increases in subjective well-being.

The qualitative interviews will give an in-depth insight into the lived experiences of participants. The qualitative aspect and the Bourdieusian perspective analyses will provide a unique insight into how participants make sense of their experience. This will allow for a full exploration and understanding of social capital and well-being in higher education labour activation programmes through a Bourdieusian perspective.

\section{References}

Andersen, S. H. (2008) 'The short- and long-term effects of government training on subjective well-being', European Sociological Review, 24(4), pp. 451-462.

Bótas, P., and Huisman, J. (2013) 'A Bourdieusian analysis of the participation of Polish students in the ERASMUS programme: cultural and social capital perspectives', Higher Education, 66(6), pp. 741-754.

Creed, P. A., Bloxsome, T. D., and Johnston K. (2001) 'Self-esteem and self-efficacy outcomes for unemployed individuals attending occupational skills training programs', Community, Work \& Family, 4(3), pp. 285-303.

Damme, D. and K. Kärkkäinen (2011) 'OECD education today crisis survey 2010: the impact of the economic recession and fiscal crisis on education in OECD countries', OECD Education Working Papers, 56, Paris: OECD Publishing. 
Department of Education and Skills (2018, June 4) 'Government launch

Springboard+ 2018'. Available at: https://www.education.ie/en/Press-Events/Press-

Releases/2018-press-releases/PR18-06-04.html (Accessed: 31 October 2018).

Department of Education and Skills (2016) Investing in National Ambition: A Strategy for Funding Higher Education. Available at:

https://www.education.ie/en/Publications/Policy-Reports/Investing-in-National-

Ambition-A-Strategy-for-Funding-Higher-Education.pdf (Accessed: 30 October 2018).

Department of Education and Skills (2015) National Skills Strategy 2025. Dublin: Government Publications Office.

Department of Education and Skills (2014) ICT Skills Action Plan 2014-2018. Available at: https://www.education.ie/en/Publications/Policy-Reports/ICT-SkillsAction-Plan-2014-2018.pdf (Accessed: 31 October 2018).

Department of Education and Skills (2011a) ICT Action Plan: Meeting the high-level skills needs of enterprise in Ireland.

Department of Education and Skills (2011b) National Strategy for Higher Education 2030: Report of the Strategy Group. Dublin: Government Publications Office.

Diener, E., Wirtz, D., Tov, W., Kim-Prieto, C., Choi. D., Oishi, S., and Biswas-Diener, R. (2009) 'New measures of well-being: flourishing and positive and negative feelings', Social Indicators Research, 39, pp. 247-266.

Harker, J.K. (1984) 'On reproduction, Habitus and education', British Journal of Sociology of Education, 5(2), pp. 117-127.

Helliwell, J. and Putnam, R. (2007) 'Education and Social Capital', Eastern Economic Journal, 33(1), pp. 1-19.

Higher Education Authority (2016) Developing talent, changing lives: an evaluation of Springboard 2011-2016

McArdle, S., Waters, L., Briscoe, J. P. and Hall, D. T. (T. (2007) 'Employability during unemployment: Adaptability, career identity and human and social capital', Journal of Vocational Behavior, 71(2), pp. 247-264.

McGuinness, S., O'Connell, P. and Kelly, E. (2014) 'The impact of training programme type and duration on the employment chances of the unemployed in Ireland', The Economic and Social Review, 45(3), pp. 425-450.

Milligan, K. Moretti, E., and Oreopoulos, P. (2004) 'Does education improve citizenship? Evidence from the United States and the United Kingdom', Journal of Public Economics, 88(9-10), pp. 1667-1695. 
Nordlund, M. (2011) 'Who are the lucky ones? Heterogeneity in active labour market policy outcomes', International Journal of Social Welfare, 20(2), pp. 144-155.

Organisation for Economic Cooperation and Development (2017) Overview of the Irish higher education system", in Supporting Entrepreneurship and Innovation in Higher Education in Ireland, OECD Publishing, Paris/EU, Brussels.

Organisation for Economic Cooperation and Development (2010) Social capital, human capital and health: What is the evidence? Available at:

https://www.oecd.org/edu/research/45760738.pdf (Accessed: 26 January 2017).

Reay, D. (2004). 'It's All Becoming a Habitus': Beyond the Habitual Use of Habitus in Educational Research. British Journal of Sociology of Education, 25(4), 431-444.

Retrieved from http://www.jstor.org/stable/4128669

Sage, D. (2014). Do Active Labour Market Policies Promote the Well-Being, Health and Social Capital of the Unemployed? Evidence from the UK. Social Indicators Research, 124(2), 319-337.

Scrivens, K. and Smith, C. (2013) 'Four interpretations of social capital', OECD Statistics Working Papers, 2013/06, Paris: OECD Publishing.

Stiglitz, J., Sen, A., and Fitoussi, J. -P. (2009) Report by the commission on the Measurement of Economic Performance and Social Progress (French Commission on the Measurement of economic Performance and Social Progress).

Strandh, M. (2000) 'Different exit routes from unemployment and their impact on mental well-being: The role of the economic situation and the predictability of the life course', Work, Employment and Society, 14(3), pp. 459-479. 